\title{
Application of triamcinolone acetonide paste to the endotracheal tube reduces postoperative sore throat: a randomized controlled trial
}

\section{L'application d'une pâte d'acétonide de triamcinolone à la sonde endotrachéale réduit les maux de gorge postopératoires: une étude randomisée contrôlée}

\author{
Sun Young Park, MD • Sang Hyun Kim, PhD • Se Jin Lee, MD • \\ Won Seok Chae, PhD • Hee Cheol Jin, PhD · Jeong Seok Lee, PhD • \\ Soon Im Kim, PhD $\cdot$ Kyung Ho Hwang, PhD
}

Received: 15 November 2010/ Accepted: 14 February 2011/Published online: 26 February 2011

(C) Canadian Anesthesiologists' Society 2011

\begin{abstract}
Purpose This study was performed to examine whether applying triamcinolone acetonide paste as a lubricant to endotracheal tubes (ETTS) reduces the incidence and severity of postoperative sore throat (POST) more effectively than applying chlorhexidine gluconate jelly.

Methods This was a randomized controlled clinical trial. Patients enrolled in the study were ages 20 to $70 \mathrm{yr}$, American Society of Anesthesiologists' physical status I and II, and scheduled for elective laparoscopic cholecystectomy. The patients were divided randomly into two groups, the chlorhexidine group and the triamcinolone group. Prior to endotracheal intubation, ETTs in the chlorhexidine group were lubricated with $0.1 \%$ chlorhexidine gluconate jelly, whereas the ETTs in the triamcinolone group were lubricated with $0.1 \%$ triamcinolone acetonide paste $0.5 \mathrm{mg}$. During the $24 \mathrm{hr}$ after the operation, we recorded the incidence and severity of POST and the incidence of cough, hoarseness, dysphagia, nausea, and dry throat.
\end{abstract}

Results Of the 150 patients initially enrolled, 143 patients were included in the study. The incidence of POST

S. Y. Park, MD $(\bowtie) \cdot$ S. J. Lee, MD · S. I. Kim, PhD

Department of Anesthesiology and Pain Medicine,

Soonchunhyang University Hospital, 657 Hannam-Dong,

Yongsan-gu, Seoul 140-743, South Korea

e-mail: sunnypark97@gmail.com

S. H. Kim, $\mathrm{PhD}$ - W. S. Chae, $\mathrm{PhD}$ - H. C. Jin, $\mathrm{PhD}$.

J. S. Lee, $\mathrm{PhD} \cdot \mathrm{K}$. H. Hwang, $\mathrm{PhD}$

Department of Anesthesiology and Pain Medicine,

Soonchunhyang University Hospital, Bucheon, Korea was significantly lower in the triamcinolone group compared with the chlorhexidine group (difference $=52.4 \%$; $95 \%$ confidence interval, $36.8 \%$ to $64.2 \%$; $P<0.001)$. The severity score for the triamcinolone group was significantly lower than that for the chlorhexidine group. The frequencies of coughing, hoarseness, dysphagia, nausea, and dry throat were similar in the two groups for the first $24 \mathrm{hr}$ after surgery.

Conclusions Triamcinolone acetonide paste applied along the length of the ETT resulted in clinically important and statistically significant decreases in the incidence and severity of POST compared with the application of chlorhexidine jelly. (ClinicalTrials.gov number, CT00908817).

\footnotetext{
Résumé

Objectif Cette étude a été réalisée afin d'observer si la pâte de triamcinolone, appliquée pour lubrifier les sondes endotrachéales (SET), réduisait l'incidence et la gravité des maux de gorge postopératoires de façon plus efficace que la gelée de gluconate de chlorhexidine.

Méthode Cette étude clinique randomisée contrôlée a recruté des patients ASA I-II (classification de l'American Society of Anesthesiologists) âgés de 20 à 70 ans et devant subir une cholécystectomie par laparoscopie non urgente. Les patients ont été randomisés en deux groupes. Dans le groupe chlorhexidine, les SET ont été lubrifiés avec de la gelée de gluconate de chlorhexidine à 0,1\%, alors que dans le groupe triamcinolone, les SET ont été lubrifiés avec $0,5 \mathrm{mg}$ de pâte d'acétonide de triamcinolone à 0,1\% avant l'intubation endotrachéale. L'incidence et la gravité des maux de gorge postopératoires et l'incidence de toux,
} 
d'enrouement, de dysphagie, de nausée et de gorge sèche ont été enregistrées pendant les 24 h suivant l'opération.

Résultats Parmi les 150 patients recrutés au début de l'étude, 143 ont été inclus. L'incidence des maux de gorge postopératoires était significativement plus basse dans le groupe triamcinolone que dans le groupe chlorhexidine (différence $=52,4 \%$, intervalle de confiance $95 \%$ : $36,8 \%$ à $64,2 \%, P<0,001)$. Le score de gravité était significativement plus bas dans le groupe triamcinolone que dans le groupe chlorhexidine. La fréquence de la toux, de l'enrouement, de la dysphagie, de la nausée et / ou de gorge sèche était semblable dans les deux groupes durant les premières $24 \mathrm{~h}$ après la chirurgie.

Conclusion Lapâte d'acétonide de triamcinolone appliquée sur toute la longueur de la SET a entraîné des réductions importantes d'un point de vue clinique et statistiquement significatives de l'incidence et de la gravité des maux de gorge postopératoires par rapport à la gelée de chlorhexidine. (ClinicalTrials.gov numéro, NCT00908817).

Postoperative sore throat (POST) is a minor complication, but it can cause patients a great deal of discomfort. Furthermore, POST is difficult to moderate, even when the operative pain has been controlled successfully by administration of systemic analgesic medications. Thus, POST remains an important issue, and several trials have been performed in an effort to attenuate POST. Most measures recommended to reduce this complication (e.g., use of fluidfilled cuffs and limiting cuff pressures) have been directed at limiting physical trauma that may result from airway instrumentation and manipulation. ${ }^{1,2}$ Additionally, some groups have evaluated pharmacological interventions as a means of reducing POST. However, no single drug has been widely accepted in the clinical community for this indication. $^{3}$

Several lubricating agents for tracheal tubes have been assessed in terms of their ability to decrease the incidence of POST; however, reports have indicated varying rates of success. ${ }^{4-6}$ Lubrication of the tracheal tube may be useful to minimize the mucosal injury by facilitating its passage through the pharynx and to reduce pulmonary aspiration. ${ }^{7}$ Additionally, topical steroids as lubricating agents are good options for POST. This is a reasonable strategy to provide targeted therapy because local irritation and inflammation of the tracheal mucosa may be the primary causes of POST. ${ }^{6,8,9}$ The application of betamethasone gel over the tracheal tube has been reported to be effective in reducing POST, cough, and hoarseness. ${ }^{6,8}$

Triamcinolone acetonide is less potent but more active as a topical glucocorticoid. Unlike betamethasone, the effects of triamcinolone acetonide on POST are unclear. ${ }^{10} \mathrm{We}$ hypothesized that triamcinolone acetonide may reduce the incidence and severity of POST more effectively than other lubricating agents. To evaluate this, we compared the effects of triamcinolone acetonide paste applied as a lubricant along the length of the endotracheal tube (ETT) with the application of chlorhexidine jelly, a commonly used lubricant.

\section{Methods}

This randomized controlled trial was approved by the Institutional Review Board of Soonchunhyang University of Korea. All participants provided written informed consent prior to enrolment. The target population consisted of patients with American Society of Anesthesiologists' physical status I and II who were ages 20 to $70 \mathrm{yr}$ and scheduled for elective laparoscopic cholecystectomy from June 2008 to May 2009. Exclusion criteria included patients with a history of recent respiratory tract infection or sore throat, preoperative use of analgesics or steroids, and risk factors for oral cavity infection. Also excluded from the analysis were patients who required more than one attempt at intubation, those with a nasogastric tube, those where the duration of tracheal intubation was $<60 \mathrm{~min}$ or $>300 \mathrm{~min}$, and/or those who vomited during the study period.

Patients were divided randomly into two groups following simple randomization procedures using a computergenerated random number table. Sealed opaque envelopes containing the randomization sequence were used to ensure allocation concealment. All ETTs were prepared by a single investigator just before intubation. Patients in the chlorhexidine group were tracheally intubated with an ETT lubricated with $0.1 \%$ chlorhexidine gluconate jelly, and those in the triamcinolone group were tracheally intubated with an ETT lubricated with $0.1 \%$ triamcinolone acetonide paste $0.5 \mathrm{mg}$. A volume of $0.5 \mathrm{~mL}$ of each agent was aspirated using a 1-mL syringe and applied along the tracheal tube. The ETT was lubricated from the distal tip to a distance of $17 \mathrm{~cm}$, and the cuff was fully inflated during its preparation to ensure that the lubricants were applied uniformly. After the two agents were applied along the tracheal tube, they were indistinguishable one from the other. The anesthesiologists were given the lubricated tracheal tubes during laryngoscopy, so they were unaware of the lubricant used. All anesthetic procedures were performed by two experienced anesthesiologists who were blinded to the group allocation. The investigators who collected the data and interviewed patients did not perform the procedures, and they were blinded to the group allocation. All patients were also blinded to group allocation.

The patients were premedicated with glycopyrrolate $0.2 \mathrm{mg} \mathrm{im}$. In the operating room, monitoring consisted of 
three-lead electrocardiography, noninvasive arterial blood pressure, pulse oximetry, and end-tidal $\mathrm{CO}_{2}$. Induction of anesthesia was achieved with fentanyl $100 \mu \mathrm{g}$ and propofol $2 \mathrm{mg} \cdot \mathrm{kg}^{-1}$, which was followed by rocuronium $0.6 \mathrm{mg} \cdot \mathrm{kg}^{-1} i v$. Before tracheal intubation, ventilation was controlled with $100 \%$ oxygen via a face mask. Direct laryngoscopy using a Macintosh \#3 blade and tracheal intubation were performed three minutes after the rocuronium injection. The patients' tracheas were intubated with a high volume/low pressure tracheal tube (Endotracheal tube; EM Euro Medical, Selangor, Malaysia) with internal diameters of 8.0 or $7.0 \mathrm{~mm}$ for male and female patients, respectively. Immediately after intubation, the tracheal tube cuff was inflated with room air until no air leakage could be heard at a peak airway pressure of $20 \mathrm{~cm} \mathrm{H}_{2} \mathrm{O}$. Then, the cuff pressure was adjusted from 8 to $15 \mathrm{mmHg}$ using a handheld pressure gauge (Portex Cuff Inflator/ Pressure Gauge; SIMS Portex, Hythe, Kent, UK). Following intubation, all patients received dexamethasone $10 \mathrm{mg} i v$ for nausea and vomiting prophylaxis. Anesthesia was maintained with $50 \% \mathrm{O}_{2}$ in air, 7 to 8 vol\% of desflurane, and rocuronium. The end-tidal $\mathrm{CO}_{2}$ was maintained from 35 to $40 \mathrm{mmHg}$. To maintain the intracuff pressure from 8 to $15 \mathrm{mmHg}$, the intracuff volume was adjusted every $15 \mathrm{~min}$ during the end-inspiratory phase using a handheld pressure gauge.

At the end of surgery, all patients received pyridostigmine $10 \mathrm{mg}$ and glycopyrrolate $0.2 \mathrm{mg} i v$, and their lungs were ventilated with $100 \% \mathrm{O}_{2}$ until they were fully awake and had recovered from muscle relaxation. After gentle suctioning of oral secretions, the cuff was deflated fully, and the ETT was removed. Oxygen was administered via a face mask, and the patients were transferred to the postanesthesia care unit. We recorded episodes of coughing during tracheal extubation, the presence of blood in the oropharyngeal secretion or on the tracheal tube after extubation, and the duration of tracheal intubation. All patients received fentanyl intravenously after the operation when they complained of operative wound pain. We did not restrict the use of fentanyl postoperatively, but no other analgesic was used.

The incidence and severity of POST were determined by direct questions ${ }^{11}$ one, six, and $24 \mathrm{hr}$ after the operation. The severity of POST was graded using a four-point scale ( 0 to 3 ): 0 , no sore throat; 1 , mild sore throat; 2 , moderate sore throat; and 3, severe sore throat. We asked the following questions: "Do you have a sore throat? If so, would you call it mild, moderate, or severe? "Additionally, the incidence of POST during the $24 \mathrm{hr}$ after the operation was determined based on these data. A patient was considered to have experienced POST if $\mathrm{s} /$ he reported a sore throat at any of the three time periods. Wound pain was recorded at the same times. Pain was measured using a $10-\mathrm{cm}$ horizontal visual analogue scale (VAS) anchored with " 0 " on one end and " 10 " on the other. Complaints of cough, hoarseness, dysphagia (difficulty on swallowing), nausea, and dry throat were recorded using direct questions during the $24 \mathrm{hr}$ after the operation. The total dose of fentanyl administered during induction and during the $24 \mathrm{hr}$ after the operation was also recorded.

\section{Statistical considerations}

The Student's $t$ test was used to compare between-group differences in wound pain VAS score, and differences in the total dose of fentanyl administered both during induction and during the $24 \mathrm{hr}$ after the operation. Betweengroup differences in the incidence of coughing during tracheal extubation, the presence of blood in the oropharyngeal secretions or on the tracheal tube after extubation, POST, cough, hoarseness, dysphagia, nausea, and dry throat for $24 \mathrm{~h}$ after the operation were analyzed using the $\chi^{2}$ test or Fisher's exact test when the expected values in any of the cells of a contingency table were below 5. The severity scores for POST were compared using the MannWhitney $U$ test. The results are expressed as means (SD), absolute numbers, or median and range of $25^{\text {th }}$ to $75^{\text {th }}$ percentiles. The SPSS ${ }^{\circledR}$ software version $14.0 \mathrm{~K}$ for Windows $^{\circledR}$ (SPSS, Chicago, IL, USA) was used for statistical analysis. All reported $P$ values are two-sided. The primary outcome variable of this study was the incidence of POST during the $24 \mathrm{hr}$ after the operation. Secondary outcome variables included the severity of POST and the incidences of cough, hoarseness, dysphagia, nausea, and dry throat during the $24 \mathrm{hr}$ after the operation.

We considered a $50 \%$ relative reduction in the incidence of POST to be clinically significant. The results of our pilot study indicated that the incidence of POST was $55 \%$. Power analysis ( $\alpha=0.05$ [2-sided] and $\beta=0.10)$ showed that 70 patients were required in each group to detect a $50 \%$ reduction in the incidence rate. To compensate for potential dropouts, 150 patients were enrolled in this study.

\section{Results}

Of the 150 patients initially enrolled in the study, seven were excluded from the analysis (four in the chlorhexidine group and three in the triamcinolone group). Two patients had need of more than one intubation attempt; three patients vomited during the study period, and two patients were excluded because the duration of tracheal intubation was $<60$ min (Figure). Characteristics of the remaining 143 subjects are summarized in Table 1.

During the $24 \mathrm{hr}$ after the operation, 14 of 72 (19.4\%) patients in the triamcinolone group experienced a sore 
Figure Study enrolment and randomization

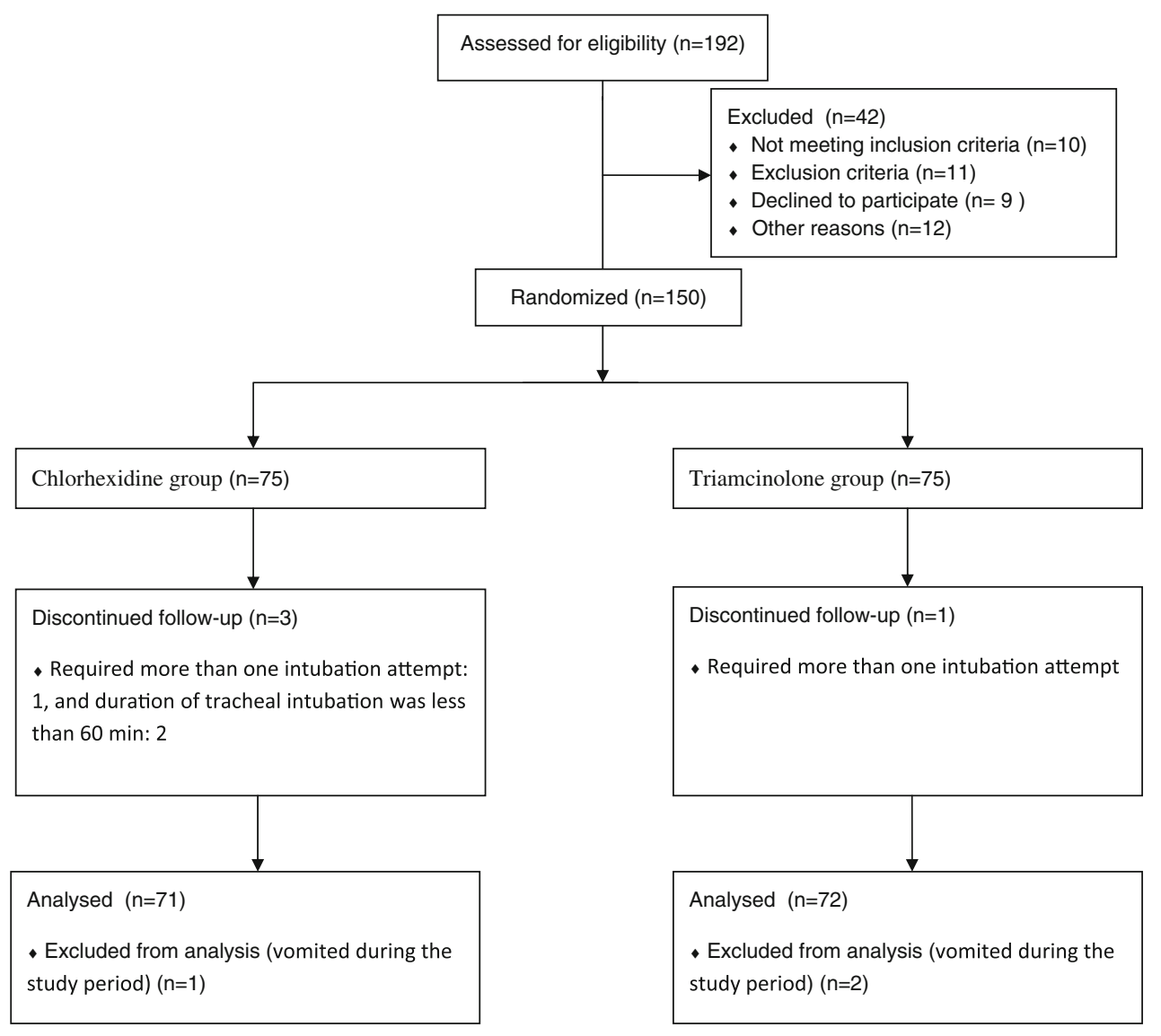

Table 1 Patient characteristics

\begin{tabular}{lll}
\hline Groups & Chlorhexidine group $(n=71)$ & Triamcinolone group $(n=72)$ \\
\hline Age (yr) & $45.3(22$ to 70$)$ & $49.7(25$ to 70$)$ \\
Sex (male/female) & $27 / 44$ & $32 / 40$ \\
Weight (kg) & $65.5(12.6)$ & $61.9(10.1)$ \\
ASA (I/II) & $54 / 17$ & $50 / 22$ \\
Propofol (mg) & $114.6(9.5)$ & $117.4(10.2)$ \\
Rocuronium (mg) & $44.8(5.3)$ & $43.5(5.1)$ \\
Duration of tracheal intubation (min) & $111.7(38.4)$ & $112.0(44.7)$ \\
\hline
\end{tabular}

Data are given as the mean (range), mean (SD), absolute numbers or median ( $25^{\text {th }}$ to $75^{\text {th }}$ percentiles). There was no significant difference between the groups. ASA $=$ American Society of Anesthesiologists

throat compared with 51 of $71(71.8 \%)$ patients in the chlorhexidine group (difference $=52.4 \%$; 95\% CI, 36.8\% to $64.2 \% ; P<0.001$ ) (Table 2). The incidences of POST according to the severity scores are listed in Table 3 . The severity scores in the triamcinolone group were significantly lower at all time points than those in the chlorhexidine group. One patient in the triamcinolone group suffered from a severe sore throat. No significant differences between the two groups were found in the incidences of cough, hoarseness, dysphagia, nausea, or dry throat (Table 2).

\section{Discussion}

In this study, we found that the application of triamcinolone paste over the tracheal tube resulted in clinically important and statistically significant decreases in the incidence and severity of POST compared with the application of chlorhexidine jelly.

Tracheal intubation can cause laryngeal trauma posteriorly over the cricoid plate, along the vocal processes of the arytenoids, and along the anterior tracheal wall. ${ }^{12,13}$ The application of triamcinolone paste along the $17-\mathrm{cm}$ 
Table 2 Clinical outcomes

\begin{tabular}{|c|c|c|c|c|}
\hline & Chlorhexidine group $(n=71)$ & Triamcinolone group $(n=72)$ & Difference $(95 \% \mathrm{CI})$ & $P$ values \\
\hline Coughing during extubation & $49(69.0 \%)$ & $44(61.1 \%)$ & $7.9(-7.7$ to 23.4$)$ & 0.382 \\
\hline Blood in the secretions or tube & $0(0 \%)$ & $1(1.4 \%)$ & $-1.4(-4.1$ to 1.3$)$ & 1.000 \\
\hline Doses of fentanyl administered $(\mu \mathrm{g})$ & $139.2(44.9)$ & $140.9(47.7)$ & $-1.7(-19.4$ to 12.1$)$ & 0.648 \\
\hline \multicolumn{5}{|l|}{ Wound pain VAS (0 to 10 ) } \\
\hline $1 \mathrm{hr}$ & $5.3(4.3$ to 5.8$)$ & $5.5(4.3$ to 5.9$)$ & $-0.2(-1.2$ to 0.9$)$ & 0.841 \\
\hline $6 \mathrm{hr}$ & $3.2(3.2$ to 4.4$)$ & $3.4(3.2$ to 4.3$)$ & $-0.2(-0.8$ to 0.7$)$ & 0.941 \\
\hline $24 \mathrm{hr}$ & 1.9 (1.8 to 2.9$)$ & 1.7 (1.7 to 2.5$)$ & $-0.2(-0.4$ to 0.9$)$ & 0.447 \\
\hline \multicolumn{5}{|l|}{ During the $24 \mathrm{hr}$ after the operation } \\
\hline \multicolumn{5}{|l|}{ Primary outcome } \\
\hline POST & $51(71.8 \%)$ & $14(19.4 \%)$ & $52.4 \%$ (36.8 to 64.2$)$ & $<0.001$ \\
\hline \multicolumn{5}{|l|}{ Secondary outcomes } \\
\hline Cough & $8(11.3 \%)$ & $17(23.6 \%)$ & $-12.3 \%(-24.5$ to 35.6$)$ & 1.000 \\
\hline Hoarseness & $40(56.3 \%)$ & $31(43.1 \%)$ & $13.2 \%(-3.0$ to 29.4$)$ & 0.113 \\
\hline Dysphagia & $16(22.5 \%)$ & $18(25.0 \%)$ & $-2.5 \%(-16.4$ to 11.4$)$ & 0.730 \\
\hline Nausea & $6(8.5 \%)$ & $14(19.4 \%)$ & $-10.9 \%(-22.1$ to 0.3$)$ & 0.059 \\
\hline Dry throat & $8(11.3 \%)$ & $12(16.7 \%)$ & $-5.4 \%(-16.7$ to 5.9$)$ & 0.354 \\
\hline
\end{tabular}

Data are given as the mean (range), mean (SD), absolute numbers or median $\left(25^{\text {th }}\right.$ to $75^{\text {th }}$ percentiles). CI $=$ confidence interval; VAS $=$ visual analogue scale; POST $=$ postoperative sore throat

Table 3 Severity scores of postoperative sore throat

\begin{tabular}{|c|c|c|c|c|c|c|c|c|c|}
\hline \multirow[t]{2}{*}{ Severity score } & \multicolumn{4}{|c|}{ Chlorhexidine group $(n=71)$} & \multicolumn{4}{|c|}{ Triamcinolone group $(n=72)$} & \multirow[t]{2}{*}{$P$ value } \\
\hline & 0 & 1 & 2 & 3 & 0 & 1 & 2 & 3 & \\
\hline $1 \mathrm{hr}$ & 28 & 12 & 8 & 23 & 68 & 3 & 0 & 1 & $<0.001$ \\
\hline $6 \mathrm{hr}$ & 40 & 14 & 11 & 6 & 61 & 10 & 0 & 1 & $<0.001$ \\
\hline $24 \mathrm{hr}$ & 54 & 13 & 4 & 0 & 68 & 4 & 0 & 0 & 0.001 \\
\hline
\end{tabular}

Data are the numbers of patients. Severity score: 0, none; 1, mild; 2, moderate; and 3, severe. Scores were obtained $1 \mathrm{hr}, 6 \mathrm{hr}$, and $24 \mathrm{hr}$ after the operation

length of the tracheal tube that comes into contact with the posterior pharyngeal wall, vocal cords, and trachea markedly reduced POST. Reduced inflammation and edema due to the local steroid application may account for these findings. Corticosteroids reduce the production of cytokines and other inflammatory mediators, such as prostaglandins and leukotrienes, by inhibiting phospholipase A2 and cyclooxygenase 2 during inflammation. The anti-inflammatory action of topical corticosteroids allows effective inhibition of inflammatory or ulcerative lesions in the mucosa. ${ }^{14}$

Several studies using topical steroid lubricants to prevent POST have been reported. In 1990, Stride ${ }^{15}$ concluded that $1 \%$ hydrocortisone water-soluble cream did not effectively reduce the incidence of POST; however, the hydrocortisone was applied to only $5 \mathrm{~cm}$ above the cuff. In other investigations ${ }^{6,8}$ and in the present study, the topical steroid agent was applied to a longer portion of the tracheal tube (15 to $17 \mathrm{~cm}$ from the tip) sufficient to cover the entire area of contact between the tube and mucosa, and beneficial effects of the topical steroid were observed. Ayoub et $a l^{8}{ }^{8}$ reported that the widespread application of betamethasone gel significantly reduced the incidence and severity of POST, cough, and hoarseness. Sumathi et al. ${ }^{6}$ obtained similar results using betamethasone gel.

Although these previous studies ${ }^{6,8}$ demonstrated the effect of topical steroid application via the tracheal tube, the present study was performed to investigate the effects of triamcinolone acetonide rather than betamethasone. Triamcinolone has one-fifth the glucocorticoid activity of betamethasone, and the dose of triamcinolone used in the present study was equivalent to $0.4 \mathrm{mg}$ of prednisone, which is a lower dose than that used in two previous studies (Ayoub et al., ${ }^{8}$ betamethasone equivalent to $3 \mathrm{mg}$ prednisone; and Sumathi et al., ${ }^{6}$ betamethasone equivalent to $4 \mathrm{mg}$ prednisone). In the present study, we found a $19.4 \%$ 
incidence of POST, which is lower than those in previous studies using betamethasone (43\% incidence, Ayoub et al. ${ }^{8}$ and $40 \%$ incidence, Sumathi et al. ${ }^{6}$ ). The acetonide component markedly enhances the penetration properties of triamcinolone, making it more active topically. ${ }^{16}$ These properties may have caused triamcinolone acetonide to be more effective than betamethasone. Although the betamethasone doses used previously were within the safe clinical range, a lower, less potent dose of triamcinolone has an advantage over betamethasone given the potential adverse effects associated with steroid use, including infections such as candidiasis, numbness, and dry mouth and throat. Moreover, triamcinolone acetonide contains two preservatives, methylparaben and propylparaben, which are effective antibacterial and antifungal agents commonly used as preservatives in foods, beverages, and pharmaceuticals. ${ }^{17}$

Chlorehexidine gluconate jelly is used frequently for lubrication. Thus, we used chlorhexidine gluconate jelly for comparison with triamcinolone acetonide paste. Chlorhexidine may increase the incidence of sore throat because it can irritate the mucosa. It is possible that the differences seen were due to an increase in POST in the chlorhexidine group rather than a reduction in the triamcinolone group. However, there was no significant difference in the incidence of POST between unlubricated and lubricated tubes in previous studies using chlorhexidine gluconate-containing jelly as a lubricant. ${ }^{4,5} \mathrm{~A}$ potentiating effect of lubrication in reducing POST was also seen in one study. ${ }^{18}$ Additionally, the incidence of POST in the triamcinolone group in the present study was lower than those described in previous reports. Thus, although we cannot exclude the effects of chlorhexidine gluconate jelly, we could still identify a preventive effect of triamcinolone acetonide on POST. Additionally, all of our subjects underwent laparoscopic cholecystectomy, the same analgesics were used in both groups, and we confirmed that the severity of postoperative pain and the dose of analgesics used during the study period did not differ between the groups. Thus, we could exclude a potential distraction effect.

The incidence of POST in the chlorhexidine group was higher than expected ${ }^{1,19}$ and higher than in the study reported by Ayoub et al. ${ }^{8}$ despite the use of the same lubricant. Additionally, unlike previous studies, ${ }^{6,8}$ the incidences of cough and hoarseness in the present study were not decreased significantly by a topical steroid. The tracheal tube may have been relatively large for our patients ${ }^{20}$ and although we adjusted the intracuff pressure, it was likely to be higher in our patients ${ }^{2}$ than in previous studies because of the increased abdominal pressure created by the $\mathrm{CO}_{2}$ gas. Additionally, more female than male patients were included in the present study population, which may have increased the incidence of POST. ${ }^{21}$ Laparoscopic cholecystectomy is a minimally invasive operation that causes mild pain, thus patients are given relatively low doses of systemic analgesics. This may be another explanation for the high incidence of POST.

The fact that all patients received dexamethasone $10 \mathrm{mg}$ intravenously was another limitation of this study. Some studies have demonstrated that preoperative intravenous administration of dexamethasone reduces the incidence of POST significantly. ${ }^{22-24}$ We used a similar dose of dexamethasone as used in these studies, which may have conflicted with the proposed effect of the lubricants. In our study, however, both groups received the same dose of dexamethasone following intubation. The difference in the incidence of POST between the two groups was considered to be based on the effects of the lubricants.

In conclusion, our results indicated that applying triamcinolone acetonide paste along the length of the ETT can reduce the incidence and severity of POST compared with applying chlorhexidine gluconate jelly.

Competing interests None declared.

\section{References}

1. McHardy FE, Chung F. Postoperative sore throat: cause, prevention and treatment. Anaesthesia 1999; 54: 444-53.

2. Combes $X$, Schauvliege $F$, Peyrouset $O$, et al. Intracuff pressure and tracheal morbidity: influence of filling with saline during nitrous oxide anesthesia. Anesthesiology 2001; 95: 1120-4.

3. Scuderi PE. Postoperative sore throat: more answers than questions. Anesth Analg 2010; 111: 831-2.

4. Loeser EA, Kaminsky A, Diaz A, Stanley TH, Pace NL. The influence of endotracheal tube cuff design and cuff lubrication on postoperative sore throat. Anesthesiology 1983; 58: 376-9.

5. Stock MC, Downs JB. Lubrication of tracheal tubes to prevent sore throat from intubation. Anesthesiology 1982; 57: 418-20.

6. Sumathi PA, Shenoy T, Ambareesha M, Krishna HM. Controlled comparison between betamethasone gel and lidocaine jelly applied over tracheal tube to reduce postoperative sore throat, cough, and hoarseness of voice. Br J Anaesth 2008; 100: 215-8.

7. Blunt MO, Young PJ, Patil A, Haddock A. Gel lubrication of the tracheal tube cuff reduces pulmonary aspiration. Anesthesiology 2001; 95: 377-81.

8. Ayoub CM, Ghobashy A, Koch ME, et al. Widespread application of topical steroids to decrease sore throat, hoarseness, and cough after tracheal intubation. Anesth Analg 1998; 87: 714-6.

9. El Hakim M. Beclomethasone prevents postoperative sore throat. Acta Anaesthesiol Scand 1993; 37: 250-2.

10. Sobel AM, Sheiner B, Boyer R. Possible prevention of complications following endotracheal anesthesia. Anesth Analg 1964; 43: 504-9.

11. Harding CJ, McVey $F K$. Interview method affects incidence of postoperative sore throat. Anaesthesia 1987; 42: 1104-7.

12. Hilding $A C$. Laryngotracheal damage during intratracheal anesthesia. Demonstration by staining the unfixed specimen with methylene blue. Ann Otol Rhinol Laryngol 1971; 80: 565-81. 
13. Bishop MJ. Mechanisms of laryngotracheal injury following prolonged tracheal intubation. Chest 1989; 96: 185-6.

14. Derendorf H, Meltzer EO. Molecular and clinical pharmacology of intranasal corticosteroids: clinical and therapeutic implications. Allergy 2008; 63: 1292-300.

15. Stride $P C$. Postoperative sore throat: topical hydrocortisone. Anaesthesia 1990; 45: 968-71.

16. Katz M, Gans EH. Topical corticosteroids, structure-activity and the glucocorticoid receptor: discovery and development-a process of "planned serendipity". J Pharm Sci 2008; 97: 2936-47.

17. Matysova L, Hajkova R, Sicha J, Solich P. Determination of methylparaben, propylparaben, triamcinolone acetonide and its degradation product in a topical cream by RP-HPLC. Anal Bioanal Chem 2003; 376: 440-3.

18. Estebe JP, Delahaye $S$, Le Corre P, et al. Alkalinization of intracuff lidocaine and use of gel lubrication protect against tracheal tube-induced emergence phenomena. Br J Anaesth 2004; 92: 361-6.
19. Christensen AM, Willemoes-Larsen H, Lundby L, Jakobsen KB. Postoperative throat complaints after tracheal intubation. $\mathrm{Br} \mathrm{J}$ Anaesth 1994; 73: 786-7.

20. Stout DM, Bishop MJ, Dwersteg JF, Cullen BF. Correlation of endotracheal tube size with sore throat and hoarseness following general anesthesia. Anesthesiology 1987; 67: 419-21.

21. Maruyama $K$, Sakai $H$, Miyazawa $H$, et al. Sore throat and hoarseness after total intravenous anaesthesia. Br J Anaesth 2004; 92: 541-3.

22. Wang JJ, Ho ST, Lee SC, Liu YC, Liu YH, Liao YC. The prophylactic effect of dexamethasone on postoperative nausea and vomiting in women undergoing thyroidectomy: a comparison of droperidol with saline. Anesth Analg 1999; 89: 200-3.

23. Park SY, Kim SH, Lee AR, et al. Prophylactic effect of dexamethasone in reducing postoperative sore throat. Korean $\mathrm{J}$ Anesthesiol 2010; 58: 15-9.

24. Thomas $S$, Beevi $S$. Dexamethasone reduces the severity of postoperative sore throat. Can J Anesth 2007; 54: 897-901. 